consideration, and reference is made to the effect of the Jeffery Report (printed in full in an appendix).

Two detailed chapters develop the work up to the ordinary level of the General Certificate of Education, and the failure of some pupils is regarded as due to unsuitable teaching methods in primary schools. A suggested minimum syllabus for this pre-entry course is given, with a lengthy discussion of the work of the first five years in the grammar school. "Some General Teaching Topics" contains much material for careful consideration by all engaged in teaching mathematics. Far too many men and women are gallantly tackling work which is beyond their own capability as teachers, and this chapter should be of great value to them.

The chapter on the sixth form is less successful than the rest of the book, and it suffers from an attempt to deal with a big topic within the compass of 25 pages. Although expansions and infinite series come into the basic course there is no mention of the vital question of convergence. There is no mention of mass in the basic mechanics course, though one of the main teaching points in school mechanics is surely the distinction between mass and weight. In the section on analytical geometry the correspondence between a locus and an algebraical equation is developed; it could well have been extended to the realization that the curve separates the plane into areas in which the function is either positive or negative; $\mathrm{f}(x)>0$ can be so much more interesting than $f(x)=0$.

There is a sensible discussion of the mathematical library, with a good list of suitable books, and elementary books in foreign languages are recommended though none is quoted.

The place of practical work in the mathematics course receives serious attention, and a mathematics room with workshop is suggested.

Lastly, a strong plea is made for the inclusion of statistics in the school course. Even if the scope of the work given here is over-ambitious, the conclusion "that statistics, so long as it is taught as a practical subject, can help to make school mathematics more realistic" well expresses the attitude to this relatively new school subject.

Some fifteen misprints have been overlooked in this first edition, but the Association can expect confidently to need a reprinting very soon. The volume as a whole is of the standard that is expected from the Cambridge University Press. W. J. LANGFoRD

\section{A POPULAR ACCOUNT OF RADIO-ASTRONOMY}

The Changing Universe

The Story of the New Astronomy. By John Pfeiffer. Pp. $x i+244+16$ plates. (London : Victor Gollancz, Ltd., 1956.) 18s. net.

$\mathrm{W}$ E are very familiar to-day with the problem of communications between scientists and the general public, and we have recently seen considerable and successful efforts in daily and monthly journalism to provide intelligent reporting of the more exciting scientific work of the present day. A more difficult problem is set by the popular text-book, which attempts to explain a whole subject to a reader whose only background is an intelligent, but rather vague, interest. An author determined to write such a book must face rigid restrictions--no mathematics, no formulæ, are allowed; all difficult terms such as frequency, wave-length, galaxy, must be explained.

Pfeiffer has written such a book, and in it he manages to cover the whole of radio astronomy up to the middle of 1956. He started with the severe restriction of knowing no radio-astronomy at all, but he had instead the advantages of twenty years experience of scientific journalism, and of two successive tenures of a Guggenheim Fellowship which enabled him to visit and talk at some length with many of the leading radio-astronomers. His account stems directly from his interviews with the men who did the work, and the history of the subject which he provides is the best we are likely to have for some time. The book is accurate in its facts; so accurate and in sufficient detail, that it can seriously be recommended as an introduction to redio-astronomy.

The contrast between the accuracy and interest of subject-matter, and the style of writing, is remarkable. Mr. Pfeiffer is an optimist. He believes it is possible to explain radio astronomy in all its complexity to anyone able to read, and he consequently addresses himself to a public whose attention requires to be riveted to each page separately by the use of superlative, hyperbole, and simile. It is safe to say that no radio-astronomer could have written such a book, although such a style would, from them, be appropriate to short magazine articles or popular lectures. I find the style too obtrusive for comfort in such a large $\operatorname{dos} \theta$, and I would be surprised to find anyone who needed such a continuous stimulation of interest and who yet was able to read and appreciate the whole of the book. F. G. SMrth

\section{INTO SPACE}

\section{Satellites and Space Flight}

By Eric Burgess. Pp. vii + $159+14$ plates. (London : Chapman and Hall, Ltd., 1957.) 21s. net.

THIS book traces the expected future history of space-travel, from the instrumented artificial satellites which are already in being to the manned interplanetary space-ship which, Mr. E. Burgess thinks, may not come for fifty years or more. The first chapter deals with rocket motors, the dynamics of satellite orbits, and the scientific experiments which can profitably be made in unmanned satellites. The next step into space is the unmanned 'probe' missile, sent to investigate the Moon and Mars on our behalf. Mr. Burgess discusses possible circumlunar orbits, the optimum transfer ellipse from Earth to Mars, and the design and instrumentation of a lunar-probe missile. Man's first sojourn in space will probably be inside a satellite space-station, and once he feels at home in this remote outpost, his next goal will be the Moon. For, despite its unattractive climate-a near-vacuum with extremes of temperature--the Moon will be prized as a base because it occupies a favourable niche in the hill-and-valley system of gravitational potential. Mr. Burgess describes the problems of the lunar base built either above or below ground, and outlines what is known of the Moon's surface. The last chapter, on manned interplanetary travel, includes a discussion of nuclear and ion rockets, and ends with some gentle speculation on interstellar flight.

Mr. Burgess, a seasoned campaigner in the realms of interplanetary space, is a confident guide, and his prophecies may well come true, if taxpayers choose 